\title{
Teachers' Stages of Concern and Levels of Use of a Curriculum Innovation in China: A Case Study
}

\author{
Wenfeng Wang ${ }^{1}$ \\ ${ }^{1}$ Centre for Applied English Studies, University of Hong Kong, Hong Kong \\ Correspondence: Wenfeng Wang, Centre for Applied English Studies, University of Hong Kong, Pokfulam Road, \\ Hong Kong. Tel: 852-3917-2041. E-mail: wwfeng@hku
}

Received: August 12, 2013 Accepted: September 3, 2013 Online Published: September 9, 2013

doi:10.5430/ijelt.v1n1p22 URL: http://dx.doi.org/10.5430/ijelt.v1n1p22

\begin{abstract}
This paper describes a study of the implementation of a new English language curriculum for senior secondary school in China. The study applied the Concerns-Based Adoption Model and examined the stages of concern and levels of use of the new curriculum of three teachers in a secondary school in Guangdong province. The findings of the study suggest that the three teachers hold a positive view towards the new curriculum, that their concerns are characteristic of three stages - management, personal concerns and consequence, and that they are implementing the new curriculum largely at two levels - mechanical use and routine use. Uncertainty about the National Matriculation English Test, lack of teacher training, and inadequate teaching time are found to be the main factors that hinder the implementation of the new curriculum in their classrooms.
\end{abstract}

Keywords: curriculum implementation, stages of concern, levels of use

\section{Introduction}

English language education in China has been undergoing a great reform since the turn of the century. The reform, initiated by the Ministry of Education, features a major process of curriculum review. As an outcome of the review process, three new English language curricula have been produced and put to experiment: National Curriculum for ELT for Compulsory Education (Ministry of Education [MOE], 2004a), National Curriculum for ELT for Senior Middle School Education (MOE, 2003), and Curriculum Requirements for University Non-English Major Education (MOE, 2004b). Apart from a more systematic sequencing of English learning from Primary Three to university, the new curricula represent a departure from the traditional, teacher-centered and textbook-driven teaching towards a learner-oriented, educational approach, with a view to bringing about quality education in general and developing in learners the ability to use English in communication in particular (Wu \& Zhou, 2007).

In an article that traces the evolution of the English language curriculum for senior secondary school in China from 1949 against the background of Chinese national developments, Wang and Lam (2009) introduced the National Curriculum for ELT for Senior Middle School Education (MOE, 2003) (referred to as the 2003 curriculum or the new curriculum in the rest of the paper) in detail and discussed it with reference to the 1993 English language syllabus, which was the most widely implemented syllabus prior to the 2003 curriculum (see Wang \& Lam, 2009, pp.79-82 for a summary of the highlights of the two documents). The 1993 English syllabus reasonably emphasized the traditional instrumental value of English as a foreign language in China in providing access to scientific knowledge and economic development; it stressed students' communicative competence (the first time in the history of English language education in China), their independent learning and use of English. With China's adoption of an international outlook, for example, by joining the World Trade Organization in 2001, holding the 2008 Olympic Games in Beijing, and the increasing use of English for both academic and professional purposes, the importance of English can only be further enhanced in both educational policies and practices in China (pp.69-70).

The role of English in the development of Chinese learners into world citizens is highlighted in the 2003 curriculum. According to the new curriculum, the English course should help students develop in five areas: linguistic knowledge, linguistic skills, affect, learning strategies and intercultural awareness. The new curriculum aims to develop students' critical thinking ability, information analysis ability, and language use ability with a view to nourishing life-long learning (Wang \& Lam, 2009, pp.75-76). This humanistic philosophy underlying the 2003 curriculum calls for "a 
concomitant fundamental change in teachers with its associated difficulties for teachers in curricular implementation and the need for new teacher development programs" (p.65).

This study focuses on the National Curriculum for ELT for Senior Middle School Education (MOE, 2003). Its main purpose is to explore how teachers experience change in the process of implementing the new curriculum. The Concerns-Based Adoption Model (CBAM), which provides ways to study teacher change in a context of educational innovation, has been applied in this exploration. This study also aims to identify the factors that affect the implementation of the new curriculum in classrooms. The CBAM is described in Section 2 of the paper alongside empirical research applying this model, and research on the factors that affect curriculum implementation is reviewed briefly in Section 3. Section 4 details the design and conduct of this case study, including the data collected and the analysis of data. Findings about teachers' experiences in terms of their stages of concerns and levels of use of the curriculum as well as the factors that affect the implementation are presented in Section 5, with interpretations in light of literature and the context of the case school. This paper ends with conclusions drawn from this qualitative case study of three teachers. Future research on teacher change in a context of curriculum reform using CBAM and research on the implementation of the three curricula are also suggested.

\section{Concerns-Based Adoption Model (CBAM)}

As introduced in Section 1, this study applied the Concerns-Based Adoption Model (CBAM) proposed by Hall, Wallace and Dossett (1973) and further developed by Hall and Lord $(1987,2011)$. This model provides ways to study teacher change in the process of implementing an innovation by identifying teachers' stages of concern and levels of use of the innovation. On stages of concern, a set of seven categories is identified, including awareness, information, personal concerns, management, consequence, collaboration, and refocusing. Table 1 presents some typical expressions for each stage.

Table 1. Stages of concern: Typical expressions of concern about an innovation

\begin{tabular}{ll}
\hline Stage of Concern & Expression of Concern \\
\hline 6. Refocusing & I have some ideas about something that would work even better. \\
5. Collaboration & I am concerned about relating what I am doing with what my co-workers are doing. \\
4. Consequence & How is my use affecting clients? \\
3. Management & I seem to be spending all of my time getting materials ready. \\
2. Personal & How will using it affect me? \\
1. Informational & I would like to know more about it. \\
0. Awareness & I am not concerned about it.
\end{tabular}

(Adapted from Hall \& Hord, 2011, p.61)

On the use of the innovation, eight levels of how people act with a change are recognized - non-use, orientation, preparation, mechanical use, routine, refinement, integration, and renewal. Some typical behaviors at each level of use of the innovation are presented in Table 2.

Table 2. Typical behaviors at different levels of use of an innovation

\begin{tabular}{ll}
\hline Levels of Use & Behavioral Indicators of Level \\
\hline 7. Renewal & The user is seeking more effective alternatives to the established use of the innovation. \\
6. Integration & The user is making deliberate efforts to coordinate with others in using the innovation. \\
5. Refinement & The user is making changes to increase outcomes. \\
4. Routine & The user is making few or no changes and has an established pattern of use. \\
3. Mechanical & The user is making changes to better organize use of the innovation. \\
2. Preparation & The user has definite plans to begin using the innovation. \\
1. Orientation & The user is taking the initiative to learn more about the innovation. \\
0. Non-Use & The user has no interest, is taking no action. \\
\hline
\end{tabular}

(Adapted from Hord, Rutherford, Huling-Austin \& Hall, 1987, p.55) 
CBAM has been extensively applied in research into many types of educational innovations. Newhouse (2001) discusses the use of CBAM by a number of researchers concerned with the implementation of computers in schools. In particular, it reports on a longitudinal study of 73 staff members during the 1990s on the use of student-owned portable computers at a secondary school. Drawing on questionnaire data and interview data, the study found that about half of the staff was at the awareness stage, and that teachers had a relatively low level of use of computers during this project. CBAM was found to be very useful in explaining the actions of teachers, and Newhouse noted that validation of the data was important to verify its authenticity, and this could be achieved through classroom observations.

Khoboli and O'toole (2012) view a particular example of action research through the theoretical lens provided by CBAM of professional development. A small group of teachers in Lesotho used action research to investigate their understanding and practice in the midst of externally initiated change. Data was collected from teachers' discussions during this 2-year project. Teachers interacted during planning sessions, lesson observations and reflection meetings. The study found that these teachers' development and change through action research corresponded with the seven stages of concern of CBAM. The authors concluded that the demonstrated resonance between CBAM and action research is significant, given the differing orientations of the two models. They also pointed out the need to conduct further studies with larger samples and possibly from diverse areas to further explore the relationship between CBAM and action research.

CBAM was adopted as the framework in Hollingshead's (2009) study of a district-wide implementation of Rachel's Challenge, a character education program, in Rockwall, Texas. CBAM principles and strategies were used to increase awareness of the change process during the first year of implementing the program. The analysis of the data collected through CBAM identified both the concerns and extent of program adoption by teachers. CBAM was found to be able to provide administrators and campus facilitators with information necessary to develop strategies that would support teachers' advancement in the program to higher levels of implementation.

Previous research has shown that CBAM is a useful model that can be applied to study teachers' concerns and adoption of an educational change as well as to nurture teachers' professional development. As the curriculum reform undergoing in China is considerably demanding, teachers will most likely meet a multitude of challenges, "the most revolutionary of which will be to change their mindset from within; teachers need to be ready to change their beliefs about themselves as teachers before they can be motivated to enhance their own competence so as to implement the new curriculum in any reasonable way" (Wang \& Lam, 2009, p.76). Given that people are in general resistant to change (Fullan, 2001), research on teachers' concerns in the process of implementing the new curriculum and their classroom practices is most necessary.

\section{Factors Affecting Curriculum Implementation}

After systematic studies of the implementation of different curricula, Snyder, Bolin and Zumwalk (1992) and Fullan (2001) identified a set of factors that affect the implementation of a curriculum. These factors pertain to the characteristics of the change (eg. need and relevance for the change, clarity of the goals of curricular innovation, difficulty and extent of change required, quality and availability of materials), characteristics of the district (eg. history of the district's attempts at innovation, planning, administrative support, time-line and information systems, board and community), school-level factors (eg. the role of the principal, teacher-teacher relationships, teacher characteristics and orientations), and external factors such as the assistance from the government and other agencies.

In the Chinese context specifically, Zheng and Davison (2008) report in detail how three secondary teachers from three schools with different backgrounds and educational priorities in Fujian province of China change their pedagogy in the process of implementing a new curriculum. Drawing on data collected through interviews, lesson observations and documents, the study found that pedagogical change within the Chinese context is affected by three forces: internal forces such as teachers' learning experience, teaching experience, and their conceptions of teaching and learning; external forces including the implementation of the new curriculum and the National Matriculation English Test; and situated forces incorporating parental expectations and the school culture. Furthermore, the authors argue that these three forces "clash and twist in a host of subtle ways, which ultimately helps to mold the salient features of the implemented pedagogy of the three teachers" (p.173).

With a focus on teachers' beliefs and practices, Wang (2009) explores the implementation of the 2003 English curriculum for senior secondary schools in China. Data were collected via interviews and classroom observation of four teachers in two schools of different standing in Guangzhou, China. It was found that teachers' beliefs about the English as a language and its role in China, English learning and teaching are largely in line with the new curriculum, 
and that they are teaching according to the new curriculum to different degrees, regarding the teaching procedure, content and focus, types of teaching and learning activities, and the roles that they play. Individual factors (e.g. teacher learning), institutional factors (eg. the school context) and social factors (eg. culture of learning) are found to affect teachers' beliefs and pedagogy. The study calls for concerted efforts at the three levels to implement a new curriculum effectively in China.

A review of research on curriculum implementation recognizes that a range of factors need to be considered for a change to be realistic. One of the core groups of people involved is the teachers, who are usually "the main group responsible for implementing the change" (Nation \& Macalister, 2010, p.176). Teachers' concerns, beliefs, and behaviors are situated in their world of practice (Tsui, 2003). Applying the Concerns-Based Adoption Model, this study aims to explore teachers' concerns and practices in their context of work while they are implementing the new English curriculum.

\section{The Study}

\subsection{Research Questions}

This study is qualitative in nature, and it seeks to answer three questions:

1) What concerns do teachers have regarding the implementation of the new curriculum?

2) At what level(s) are teachers implementing the new curriculum in the classroom?

3) What factors facilitate the implementation, and what factors inhibit it?

\subsection{The School Setting}

The study was conducted in Hailan Senior Secondary School (pseudonym) in Guangdong province. This school is one of the sixteen provincial key secondary schools in the province. The school has a student population of 3600 . Grade 1 has about 1200 students grouped into 20 classes. Eight English teachers teach these 20 classes with four teachers teaching three classes each and the other four teaching two classes each. Each class has five teaching periods in a week and each period lasts 40 minutes.

\subsection{Participants}

Three Grade 1 teachers participated in the study. They all hold a Bachelor's degree in Teaching English as a Foreign Language (TEFL) from teachers' universities in China and have been teaching in this school since graduation from university. They are all female teachers. Alice (pseudonym), aged 25, is an Assistant Instructor with one year of teaching experience. Erin (pseudonym), aged 34, is an Instructor with 12 years of teaching experience. Steffi (pseudonym), aged 36, is a Senior Instructor with 14 years of teaching experience. She is also the panel teacher.

\subsection{Data Collection and Analysis}

Data were collected from three sources. Semi-structured interviews were conducted individually with the three teachers. The questions asked in the interviews were on teachers' perceived needs for the new curriculum, their concerns about the implementation, how it was implemented and what factors they thought affected the implementation. The interviews were conducted in Chinese and each lasted about 40 minutes. The school principal was also interviewed on his perceived needs for this new curriculum and the strategies the school had adopted for the implementation.

All interviews were voice-pen recorded, transcribed and translated into English. The English version of the transcripts were coded and dealt with through thematic analysis (Lincoln \& Guba, 1985; Stake, 1995) under the guidance of the research questions. For example, regarding teachers' stages of concern, statements that "I'm now teaching the new textbook through trial and error. What I care most is whether students think I'm an incompetent teacher, and if so, whether they will complain, or even complain to the school principal." would be labeled as Stage 2 personal concerns, where the teacher is considering how the use of an innovation affects her job security. Statements that "Learning with the new curriculum, students need to change their learning styles. They will do group projects and search for information by themselves. They may resist this new way of learning." would be categorized into Stage 4 consequence, where the teacher is concerned about the impact of the use of the innovation on their clients, that is, the students and their way of learning in particular.

Regarding the factors affecting the implementation, both facilitating factors and inhibiting factors were identified by the participants, based on which a summary list of factors across the three teachers was developed with elaborations made by each individual teacher and the source of the information. Given the subjectivity of qualitative data analysis, 
quotes from the interviewees are provided in this paper to allow for any possible different interpretations.

In addition to interviews, three 40-minute lessons, one from each teacher, were observed. Detailed notes were taken during the observation. Special attention was paid to the teaching and learning activities. After the observation, teachers were asked whether the lesson represented an established pattern of teaching in her class and if so, whether they were considering further changes, in order to delineate their levels of use of the new curriculum. Samples of student test papers were also collected from the panel teacher as supporting data indicative of the orientation of assessment of students' learning practiced in this school.

\section{Findings and Discussion}

This section reports the major findings of the study in relation to teachers' stages of concern and their levels of use of the new curriculum as well as the factors that affect the implementation in the case school.

\subsection{Teachers' Stages of Concern}

A close analysis of the interview data suggests that the three teachers have concerns that are mostly characteristic of three stages - management, personal concerns and consequence. Regarding management, they have shared concerns about managing big classes and about inadequate class time to deal with the tasks in the textbook.

I have about 60 students in my class and it's difficult to manage. I do have group work, but I can't make sure that everyone speaks. With such a big class, I can't attend to individual differences either. (Erin)

The textbook has too much content to cover. It is designed for 45-minute class periods. The English class in our school lasts only 40 minutes. It is therefore impossible for us to do all the tasks. Usually the speaking task is either lightly touched or simply skipped. (Steffi)

They have all expressed concerns over the impacts of the use of the new curriculum on themselves, for example, the high demand of the curriculum on teachers and related changes required of them:

The new curriculum is very demanding on the part of teachers. We need to change ourselves in many aspects, for example, teaching methods and classroom management. We need to improve our English proficiency as well in order to conduct more interactive teaching and create an English rich environment for students to use the language both inside and outside the classroom. It is like a long march of learning and professional development. (Steffi)

I've been puzzled for a long time. I need to make students understand the rationale of the new curriculum and make them see the importance of listening and speaking in learning English. I also need to help them develop their language use abilities. These are all very challenging tasks. (Alice)

Alice, a teacher with only one year of teaching experience, is also concerned about how she is received by her students and whether she is popular among the students in relation to the use of the new textbook:

I'm a new teacher, and I want them to like me as a teacher. One problem that I'm facing now is that the textbook has too much to cover in class. If I don't finish it and skip some tasks, I'm afraid my students will complain about the incompletion of the textbook. (Alice)

On the consequence of the reform, they have expressed their concerns about the impacts on students' learning styles. For example,

Students are used to passive learning - following teacher lectures, taking notes, and doing drills. They are not aware at all that they should be responsible for their own learning, let alone the ability to carry out independent learning. (Erin)

A recurring theme that emerges in the three teachers' interview data is the evaluation of students' learning, the reform of the National Matriculation English Test (NMET) and its washback effects on teaching and learning (Qi, 2004, 2005; Xiao, Sharpling \& Liu, 2011) in particular:

How to evaluate students' performance? Our teaching has been heavily constrained by the exams. We hope to help students develop language use abilities and at the same time help them do well in the exams. (Erin)

How will the National Matriculation English Test be reformed? Our teaching follows the direction of the exams. Students only learn what is tested. If it is confirmed that the reform of test is in accordance with the new curriculum, students will be more motivated in learning with the new curriculum. (Steffi)

According to the panel teacher, Steffi, students' performance in this school is mainly assessed by three types of tests 
administered at different times over an academic term: bi-unit tests, a mid-term test, and an end-of-term test. An examination of the sample test papers provided by Steffi found that the testing remains knowledge-based, mainly assessing students' linguistic knowledge on vocabulary and grammar. Referring to assessment, the panel teacher spelled out the difficulties they had encountered:

Teachers in our school did support formative assessment, and we designed portfolio for each student, but we never carried it out, since the portfolio will not be considered as important as NMET. This will add burden to us teachers as well, given that we haven't got much guidance on the use of portfolio so far. (Steffi)

Concerns on the inadequate information about the new curriculum were also expressed by Erin:

Although we received training for the new curriculum, we were only given a few guidelines about the curriculum. How to actually teach in the classroom has not been exemplified. Many teachers including me are lost. For example, I don't know how to deal with the new words in the reading text. (Erin)

It is clear that the three teachers in the study have concerns over the implementation of the new curriculum and that they are able to articulate their concerns. They are most anxious about the management of big classes and inadequate class time for teaching as well as the high demands the new curriculum put on them on top of students' learning styles and evaluation of their learning. These concerns in teachers' mental lives represent some of the hidden side of teaching (Freeman, 2002); they help to explain why they are teaching in the way they do. These concerns can also be considered in the evaluation of teacher performance and in the design of teacher training programs (Khoboli \& O'toole, 2012).

\subsection{Teachers' Levels of Use}

In the 40-minute session that was observed, Alice spent as much as 35 minutes on warming-up and pre-reading activities, using pictures, teacher initiated questions and student group discussions, before she handled the reading text in the last 5 minutes of the lesson. This heavy emphasis on listening and speaking seems to have originated from her belief that "Students' ability to use English in listening and speaking are what the new curriculum emphasizes" (Alice, interview). By making changes in relation to the innovation, her practices reflect the features of mechanical use of the new curriculum. When asked whether this was her usual way of teaching a reading lesson, she denied:

No no, I have not got a regular way of teaching yet. I'm still in the process of learning about the new curriculum and about teaching according to the new curriculum. Spending 35 minutes on pre-reading tasks may be too much? (Erin)

Erin taught vocabulary in the observed class. The teaching of vocabulary was carried out in the forms of multiple-choice exercises and true/false questions on the meaning of new words as well as translation of sentences using the new words. The words were presented in complete sentences that described students' lives. The teacher appeared confident, and she conducted the lesson very smoothly, and students seemed motivated and were actively engaged in the learning activities. After class, Erin confirmed that this was an established way of teaching vocabulary in her class, and that she was not considering alternatives at the time of the study. Her adoption of the new curriculum is therefore indicative the level of routine, where the teacher has an established pattern of the use of the innovation.

Steffi spent the first 20 minutes on warming-up and pre-reading tasks using pictures, teacher questions and group discussions and the other 20 minutes on a listening task that required students to look for the main idea of the passage and that of each paragraph. The lesson was well organized and well paced with a high frequency of interactions between students and between teacher and students. She confirmed in the interview that this class was typical of her teaching and that she would continue using this approach. Her teaching therefore is also at the level of routine.

Although the above discussion is based on the observation of one 40-minute session of each class, teachers' words in the interviews have further indicated their levels of use of the innovation, being routine or mechanical use of the new curriculum. In light of Fullan's (2001) argument that change is a process rather than an event, these teachers could progress to higher levels of use, for example, by evaluating the outcomes of teaching and making changes to increase outcomes, coordinating with other teachers in using the innovation and seeking more effective alternatives to the established use of the innovation.

\subsection{Factors Affecting the Implementation}

During the interviews, the three teachers talked about the factors that facilitated their teaching and those that inhibited their implementation of the new curriculum. 


\subsubsection{Facilitating Factors}

Factors that facilitated the implementation of the new curriculum in this school include advanced school facilities, competent teachers, good students, and strong leader support.

School facilities. In this key provincial school, computers and audio-video equipment are installed in every classroom, and computers with access to the Internet are installed in teachers' offices. These facilities have greatly enhanced teaching and helped teachers with lesson preparation, as Alice and Steffi highlighted in the interview:

The facilities in our schools are really very advanced. We have multimedia equipment in all classrooms. With such equipment, our teaching can be more interesting. (Alice)

To teach some topics such as black holes, pictures are necessary and useful. So we went on-line with the office computer and downloaded some pictures easily. It's very useful. We can also share the teaching courseware on the computer. (Steffi)

Teacher competence. All of the eight English teachers in Grade 1 of this school hold a BA degree in TEFL from teachers' universities in Shanghai, Shanxi or Guangdong. With an average of 10 years of teaching experience, they are either Instructors or Senior Instructors in terms of professional titles. Teachers with such experience have usually developed pedagogical competence in their teaching practice and are committed to their job (Wu \& Zhou, 2007). Their qualifications and related self-efficacy can help them translate the new curriculum, which features a learner orientation, into their teaching practice (McCormick, Ayres \& Beechey, 2006; Snyder, Bolin \& Zumwalk, 1992). Steffi, the panel teacher, highlighted this facilitating factor in the interview:

The teachers in our school in general have good language competence and teaching competence developed over the years. We are also open-minded and are very keen on learning new things. (Steffi)

Students. The students in this provincial key school have succeeded in very tough competitions, being both intelligent and diligent. Their capacity helps them to learn new things quickly, as Erin pointed out in the interview:

In a provincial key school like ours, the students are comparatively easier to teach. They learn new things quickly and are hard-working too. (Erin)

Leader support. Leaders play an important role in implementing an innovation (Fullan, 1992; Hall \& Hord, 2011). Leaders in this case school are recognized by the three teachers as a facilitating force in the implementation of the new curriculum, as Steffi stated in the interview:

Our school leaders attach great importance to the implementation of the new curriculum. The school has a team for this new curriculum, headed by the principal. The team has developed a working plan to guide the implementation. (Steffi)

The support of the school leaders is confirmed in the interview with the school principal:

One teacher suggested that we should go out and learn how other schools are implementing the new curriculum, and now we are about to take actions. Each year, we also send one or two English teachers to Britain or Australia for teacher training. (The school principal)

\subsubsection{Inhibiting Factors}

Factors that inhibited the implementation of the new curriculum in the school were also identified, relating to the NMET, teacher training, teaching hours, parents and the textbooks.

Uncertainty about NMET. All of the three teachers hold a positive view toward the new curriculum, but they are worried about the reform of NMET as NMET has been found to have great washback effects on the teaching in senior secondary schools (eg. Qi, 2004, 2005; Xiao, Sharpling \& Liu, 2011). This has been expressed explicitly by the three teachers in the interviews:

Students don't like speaking activities. Their reason is that speaking won't be tested in NMET, so why bother? I kind of agree with them. (Alice)

To tell the truth, NMET is very influential. We're much confined by it. We don't know how it will be reformed and to what extent. (Erin)

I agree that the new curriculum is better than the previous one as it emphasizes students'overall development. But what if NMET doesn't reform much and goes on testing students' knowledge on vocabulary and grammar? So to play safe, we have to teach in a more traditional way. (Steffi)

Inadequate teacher training. The three teachers are all puzzled over how the new curriculum should be adopted in 
their actual teaching. Although they attended a three-day training program in the summer before they started teaching the new textbook, they thought the training was far from adequate, as Erin stated during the interview:

The three-day teacher training in the forms of lectures and workshops was a light touch only. We were told that this was the new curriculum and then came back with some guidelines. But these guidelines are too general for the curriculum to be implemented in the classroom. Many practical issues concerning teaching are left unsolved. For example, I still don't know what the strategies for listening are and the ways to train these strategies. We're lost in the middle. We feel exhausted. (Erin)

In relation to teacher training, one frustrating experience, as described by Steffi, the panel teacher, is that after the training program there has been no communication between the training institutions and the school teachers.

We've been teaching the new textbooks for almost two terms and no one from the teacher training institutions or education bureau has ever come to listen to us. There was once a visit to our school, but that was for the curriculum in general and they only had a talk with the school principal. But the school principal might know his own subject better, which is Chinese in our case. (Steffi)

Communication between teacher trainers or the curriculum development team and the school teachers, for purposes of information sharing, classroom visiting, answering questions and giving advices, is essential for monitoring the implementation process. Lack of such communication can be detrimental; for example, this has been identified as a factor that hinders the implementation of communicative teaching in public secondary schools in Greece (Karavas-Doukas, 1995).

Insufficient teaching time. The three teachers all pointed out that they had too few class hours to deal with the tasks in the textbook. Although it is suggested that teachers use the textbooks flexibly in their working contexts and that they skip some tasks when necessary, what is skipped is often the speaking task. Alice described this in the interview:

Every week we have only five 40-minute classes and it's impossible to carry out all the tasks designed in the textbook and we have to cut some, such as speaking, because this is not tested in NMET. (Alice)

Passive students. Albeit the fact that most students in this school are diligent and quick learners, they have been successful mainly using traditional learning methods, which emphasize acquisition of linguistic knowledge of grammar and vocabulary (Jin \& Cortazzi, 2006, 2011). A change in the learning method will likely pose a great challenge to them, and some students appeared very passive in the observed lessons. Erin expressed this view:

Our students, from primary school till now, have developed a habit of following the teacher, taking notes and doing exercises. They aren't used to doing projects in groups, searching for information on their own, or using English to express themselves. This makes teaching according to the new curriculum very difficult. (Erin)

Doubtful parents. An important stakeholder in education is students' parents (Fullan, 1992). They have been found to be very influential in learners' experience of learning a foreign language (Gao, 2010). In order to implement a change, the school and teachers should gain parents' support. The school has organized information sessions on the new curriculum for parents, but some parents are still uncertain of the effects of the change, as Alice pointed out in the interview:

Students' parents care about students' score in NMET only. They worry about any possible negative impact of the new curriculum on their children's performance in NMET and thus they don't support the change. (Alice)

Problems in the textbooks. Although the textbooks were published by Peoples' Education Press, which is a prestigious press in China, they are not flawless. The three teachers all expressed their dissatisfaction with the textbooks, regarding the quantity of content, selection of topics and teacher support:

The textbooks have too much to cover. Some topics are far away from students' life, for example, the Mekong River. I think our students would like to know more about the Yangtzi River in China or the Pearl River in Guangdong in English. (Alice)

Some topics in the textbooks such as the black hole are very difficult for us to handle. We know very little about this topic. We are not an encyclopedia. (Erin)

I find that the language section in teachers' book very inadequate and it offers little help. We have to do a lot of work on our own - looking up the words in the dictionary, thinking of examples to use these words in meaningful contexts, and reading other reference books on the connotations of some words and idioms - while preparing the lesson. The textbooks surprisingly have some language errors as well. (Steffi)

These findings on the factors that affect the implementation of the new curriculum in this case study are in line with 
previous research (eg. Fullan, 2001; Snyder, Bolin \& Zumwalk, 1992; Zheng \& Davison, 2008; Wang, 2009). These factors are pertaining to the teacher, eg. teachers' competence and their sense of self-efficacy; the school context, such as student characteristics, school facilities, leader support and parents' expectations; and the social factors or external factors including public tests. This study found that in relation to the change, adequate teacher training, regular communication between teacher trainers and teachers, and the design of the textbooks that fits in the teaching context, are also important factors contributing to the implementation of the change.

\section{Conclusion}

Drawing on Concerns-Based Adoption Model, this study has examined the stages of concerns and levels of use of the new curriculum of three teachers in a secondary school in China. The three teachers' concerns are largely indicative of the characteristics of three stages: management, personal concerns and consequence. Regarding levels of use of the new curriculum, the junior teacher's practices seem to be at the level of mechanical use, and the practices of the other two more senior teachers appear to have reached the level of routine. The study has also identified the factors that affect the implementation of the new curriculum in this school. Facilitating factors include advanced school facilities, qualified teachers, good students and leader support; inhibiting factors include teachers' uncertainty about NMET, inadequate teacher training, lack of communication between teacher trainers and teachers, insufficient class time and unsupportive parents. This study has proved that the CBAM is a useful framework to explore teachers' experience in the process of implementing a curriculum reform in the Chinese context. The findings on teachers' stages of concern and their levels of use further support the argument that innovation is a process rather than an event (Fullan, 2001). These findings also provide useful basis for understanding teachers' mental lives and their practices, for designing effective teacher training programs, and for further implementing the new curriculum. Future research can explore teachers' experiences using CBAM with a larger sample and more lesson observation data. Longitudinal studies can also be conducted to trace teacher change in a context of educational innovation. Another line of research is to study the extent of implementation of the new curriculum, using the curriculum guidelines and curriculum developers' views as frames of reference while taking into account the teaching context when interpreting the research findings. Students' learning experiences with the new curriculum are also worth exploring, given the fact that the ultimate goal of teaching is to bring about effective learning to the students. As this study focuses on the implementation of National Curriculum for ELT for Senior Middle School Education (MOE, 2003), similar studies can be conducted to probe into the implementation of the other two important curricula, namely National Curriculum for ELT for Compulsory Education (MOE, 2004a) and Curriculum Requirements for University Non-English Major Education (MOE, 2004b).

\section{Acknowledgements}

The author wishes to thank the two reviewers for their constructive comments on an earlier version of this paper.

\section{References}

Freeman, D. (2002). The hidden side of the work: Teacher knowledge and learning to teach. Language Teaching, 35, 1-13. http://dx.doi.org/10.1017/S0261444801001720

Fullan, M. (2001). The new meaning of educational change. New York, NY: Teachers' College Press.

Fullan, M. (1992). Successful school improvement. Buckingham, Philadelphia: Open University Press.

Gao, X. (2010). Strategic language learning: The roles of agency and context. Bristol: Multilingual Matters.

Hall, G., \& Hord, S. (1987). Change in schools: Facilitating the process. New York, NY: State University of New York Press.

Hall, G., \& Hord, S. (2011). Implementing change: Patterns, principles, and potholes. Boston, MA: Allyn and Bacon.

Hall, G., Wallace, R. E., \& Dossett, W. (1973). A developmental conceptualization of the adoption process within educational institutions. Austin, TX: Research and Development Center for Teacher Education, The University of Texas at Austin.

Hollingshead, B. (2009). The concerns-based adoption model: A framework for examining implementation of a character education program. NASSP Bulletin, 93(3), 166-183. http://dx.doi.org/10.1177/0192636509357932

Hord, S., Rutherford, W., Huling-Austin, L., \& Hall, G. (1987). Taking charge of change. Alexander, VA: Association for Supervision and Curriculum Development. 
Jin, L. X., \& Cortazzi, M. (2006). Changing practices in Chinese cultures of learning. Language, Culture and Curriculum, 19(1), 5-20. http://dx.doi.org/10.1080/07908310608668751

Jin, L. X., \& Cortazzi, M. (Eds.) (2011). Researching Chinese learners: Skills, perceptions and intercultural adaptations. New York, NY: Palgrave Macmillan.

Karavas-Doukas, E. (1995). Teacher identified factors affecting the implementation of an EFL innovation in Greek public secondary schools. Language, Culture and Curriculum, 81, 53-68. http://dx.doi.org/10.1080/07908319509525188

Khoboli, B., \& O'toole, J. M. (2012). The concerns-based adoption model: Teachers' participation in action research. Systemic Practice and Action Research, 25,137-148. http://dx.doi.org/10.1007/s11213-011-9214-8

Lincoln, Y. S., \& Guba, E. G. (1985). Naturalistic inquiry. Newbury Park, CA: Sage.

McCormick, J., Ayres, P., \& Beechey, B. (2006). Teaching self-efficacy, stress and coping in a major curriculum reform. Journal of Educational Administration, 44, 53-70. http://dx.doi.org/10.1108/09578230610642656

Ministry of Education, China. (2003). National Curriculum for ELT for Senior Middle School Education. Beijing: People's Education Press.

Ministry of Education, China. (2004a). National Curriculum for ELT for Compulsory Education. Beijing: People's Education Press.

Ministry of Education, China. (2004b). Curriculum Requirements for University Non-English Major Education. Beijing: People's Education Press.

Nation, I. S. P., \& Macalister, J. (2010). Language curriculum design. New York and London: Routledge.

Newhouse, C. P. (2001). Applying the concerns-based adoption model to research on computers in classrooms. Journal of Research on Technology in Education, 33(5), 1-21. Retrieved from http://www.editlib.org/p/94584

Qi, L. (2004). Has a high-stakes test produced the intended changes? In L. Cheng, \& Y. Watanabe (Eds.), Washback in language testing: Research contexts and methods (pp. 171-190). Mahwah, NJ: Laurence Erlbaum \& Associates.

Qi, L. X. (2005). Stakeholders' conflicting aims undermine the washback function of a high-stakes test. Language Testing, 22(2), 142-173. http://dx.doi.org/10.1191/02655322051t300oa

Snyder, J., Bolin, F., \& Zumwalk, K. (1992). Curriculum implementation. In P. W. Jakson (Ed.), Handbook of research on curriculum implementation (pp. 402-435). New York, NY: Macmillan.

Stake, R. E. (1995). The art of case study research. Thousand Oaks, CA: Sage.

Tsui, A. B. M. (2003). Understanding expertise in teaching. Cambridge: Cambridge University Press.

Wang, W. F. (2009). Exploring teachers' experiences in curriculum implementation in China: Case studies of four secondary school English teachers. Köln: LAP LAMBERT Academic Publishing.

Wang, W. F., \& Lam, A. (2009). The English language curriculum for senior secondary school in China: Its evolution from 1949. RELC Journal, 40(1), 65-82. http://dx.doi.org/10.1177/0033688208101447

Wu, Y., \& Zhou, Y. (Eds.). (2007). EFL teacher development in China: Theory and practice. Beijing: Foreign Language Teaching and Research Press.

Xiao, Y., Sharpling, G., \& Liu, H. (2011). Washback of National Matriculation English Test on students' learning in the Chinese secondary school context. Asian TEFL, 13(3), 103-129. Retrieved from http://wrap.warwick.ac.uk/id/eprint/48126

Zheng, X. M., \& Davison, C. (2008). Changing pedagogy: Analyzing ELT teachers in China. London and New York: Continuum. 